\title{
Distribution and Co-Localization of Nitric Oxide Synthase and Argininosuccinate Synthetase in the Cat Hypothalamus*
}

\author{
Hiroyuki Isayama ${ }^{1,2}$, Hiroyuki Nakamura ${ }^{1,3,4,5}$, Hideki Kanemard ${ }^{1,2}$, Keiko KobaYashi ${ }^{6}$, Pierce C. \\ EMSON $^{7}$, Masaru KAWABUCHI ${ }^{1}$ and Nobutada TASHIRO ${ }^{2}$ \\ Department of Anatomy ${ }^{1}$, and Psychiatry ${ }^{2}$, Kyushu University School of Medicine, Fukuoka; Precursory Research for Embryonic \\ Science and Technology (PRESTO) ${ }^{3}$, Japan Science and Technology Corporation (JST), Saitama; Department of Anatomy ${ }^{4}$, Gifu \\ University School of Medicine, Gifu; Laboratory of Neural Circuit ${ }^{5}$, Kawamura Medical Society, Gifu; Department of Biochemi- \\ stry $^{6}$, Kagoshima University School of Medicine, Kagoshima, Japan; and Medical Research Council ${ }^{7}$, Molecular Neuroscience \\ Group, Cambridge, United Kingdom
}

Received October 6, 1997

Summary. Argininosuccinate synthetase (ASS) and nitric oxide synthase (NOS) comprise part of the cyclic metabolic pathway to produce nitric oxide (NO). ASS is one of the arginine synthesis enzymes which synthesizes argininosuccinate from aspartate and citrulline, and NOS forms NO and citrulline from arginine. This study examines the localization of ASS and NOS in the cat hypothalamus using nicotinamide adenine dinucleotide phosphate-diaphorase (NADPH-d) histochemistry and immunohistochemistry against ASS and NOS.

NADPH-d positive and/or ASS-immunoreactive neurons were localized in the following areas: the anterior hypothalamic area, the anterior hypothalamic nucleus, the supraoptic nucleus, the suprachiasmatic nucleus, the periventricular complex, the paraventricular nucleus, the parvocellular nucleus, the lateral hypothalamic area, the dorsomedial hypothalamic nucleus, the dorsal hypothalamic area, the posterior hypothalamic area, and the supramammillary nucleus. NOS and ASS double-labeled neurons were found in the anterior hypothalamic area, the supraoptic nucleus, the central part of the paraventricular nucleus of the hypothalamus, the lateral hypothalamic area, ventral part of the parvocellular hypothalamic nucleus, the posterior hypothalamic area, and the supramammillary nucleus. Double-labeled neurons in the hypothalamus comprised $20.7-32.0 \%$ of ASSimmunoreactive neurons and $10.2-26.3 \%$ of NOS-immunoreactive neurons. The results suggest the existence of the 'NO cycle' in situ and the physiological importance of $\mathrm{NO}$ and argininosuccinate in several regions of the cat hypothalamus.
Nitric oxide (NO) is produced by nitric oxide synthase (NOS) from arginine with the stoichiometric production of cirtulline, which requires calmodulin (PALMER and MONCADA, 1989; BREDT and SNYDER, 1990). Citrulline is converted into arginine through the arginine-citrulline cycle (HECKER et al., 1990; Mitchell et al., 1990; HATTORI et al., 1994). Citrulline is condensed with aspartate by argininosuccinate synthetase (ASS) to form argininosuccinate. Argininosuccinate is then cleaved by argininosuccinate lyase (ASL) to yield fumarate and arginine (RATNER et al., 1960). Thus, citrulline is recycled to arginine by the action of ASS and ASL, resulting in NOS, ASS and ASL comprising a cyclic metabolic pathway to produce NO.

Nitric oxide has several physiological functions in the brain. In the hypothalamus, NO has been reported to modulate the release of hormones such as noradrenalin, dopamine, corticotropin-releasing hormone, luteining hormone-releasing hormone, vasopressin, and oxytocin (KARANTH et al., 1993; RETTORI et al., 1993; RABer and Bloom, 1994; SeIlicovich et al., $1995 \mathrm{a}, \mathrm{b})$. It has also been reported that NO may modulate drinking, eating, sexual behaviors, thermoregulation and osmoregulation (CALAPAI et al., 1992; MONDA et al., 1994; VILLAR et al., 1994; BenELli et al., 1995; DE LluCA et al., 1995; MorLEY et al., 1996). These data suggest that NO plays complex and diverse roles in hypothalamic activities.

TASHIRO et al. (1985) previously reported that elec-

\footnotetext{
*This work was supported by Kaibara Morikazu Medical Science Promotion Foundation and by Japan Science and Technology Corporation.
} 
trical stimulation of the anterior hypothalamic nucleus in the cat induced emotional behaviors including threat, restlessness and aggression. Several recent reports suggest a relationship between aggressive behavior and some hypothalamic regions (FERRIS et al., 1997; OlazABAL and FerReIRA, 1997; SiEgEL and SHAIKH, 1997). Interestingly, NELSON et al. (1995) reported an increase in aggressive behavior in male mice with a targeted disruption of neuronal NOS. Because the co-localization of ASS and NOS may greatly facilitate NO production, it is of interest to examine whether ASS and NOS are co-localized in the hypothalamus.

In a prior study, NAKAMURA et al. (1991a) have demonstrated the distribution of ASS-immunoreactive neurons in the rat brain including the hypothalamus. On the other hand, localization of NOS was reported in the rat brain (VINCENT and KIMURA, 1992) using nicotinamide adenine dinucleotide phosphatediaphorase (NADPH-d) activity, a reliable marker for neuronal NOS (DAwson et al., 1991; HoPE et al., 1991). Recently, the distribution of NOS-immunoreactive neurons was also demonstrated in the rat hypothalamus (TORRES et al., 1993; VILLAR et al., 1994; YAMADA et al., 1996). In the cat brain, localization of NADPH-d active neurons was reported by MizUKAWA et al. (1989). However, a detailed distribution of ASS-immunoreactivity and NADPH-d activity in the cat hypothalamus has not been reported. Co-localization of ASSimmunoreactivity and NADPH-d activity was reported only in the rat brain (ARNT-RAMOS et al., 1992). This study made use of two specific antibodies to investigate the co-localization of ASS and NOS by double-labeling immunohistochemistry, a far more reliable method than the double staining of ASSimmunoreactivity and NADPH-d activity, in another species regularly used in physiological study.

\section{MATERIALS AND METHODS}

\begin{abstract}
Animals
Eight adult male cats, weighing 2.5-3.5 kg, were used in this study. Four cats were used for NADPH-d histochemistry and ASS immunohistochemistry, and the other four for double-labeling immunohistochemistry of ASS and NOS.
\end{abstract}

\section{Tissue preparations}

Under deep anesthesia with sodium pentobarbital (70 $\mathrm{mg} / \mathrm{kg}$ i.p.), the animals wer perfused through the aorta with $2000 \mathrm{ml}$ of cold sodium phoshate-buffered saline (PBS) ( $\mathrm{pH}$ 7.4) followed immediately by 2000 $\mathrm{ml}$ of a fixative containing $4 \%$ paraformaldehyde in $0.1 \mathrm{M}$ phosphate buffer (PB) (pH 7.4), and then by 500 $\mathrm{ml} 10 \%$ sucrose in $0.1 \mathrm{M} \mathrm{PB}$. It took about $3 \mathrm{~h}$ for the perfusion procedure. The brain was blocked and removed from the skull, and placed in $30 \%$ sucrose in $0.1 \mathrm{M} \mathrm{PB}$ at $4^{\circ} \mathrm{C}$ for 5 days. The blocks were cut into $50 \mu \mathrm{m}$ coronal sections on a freezing microtome and collected in $0.02 \mathrm{M}$ potassium phosphate-buffered saline (KPBS) ( $\mathrm{pH}$ 7.4). Series of three consecutive sections were used for NADPH-d histochemistry, ASS immunohistochemisty, and Nissl staining. In the double-labeling immunohistochemistry of ASS and NOS, every fifth section was used.

\section{NADPH-d histochemistry}

The sections were incubated in a KPBS solution containing $0.3 \%$ Triton X-100, $0.025 \% \quad \beta$-NADPH (Sigma, St. Louis, MO), and $0.025 \%$ nitro blue tetrazolium (Sigma) at room temperature for $2 \mathrm{~h}$. The sections were rinsed in KPBS, mounted on gelatinized slides, cleared in xylene and coverslipped with Permount (Fisher Scientific, Pittsburgh, PA).

\section{ASS immunohistochemistry}

The antiserum used for the rat liver ASS was prepared by immunization of rabbits with the purified enzyme in Freund's adjuvant (SAHEKI et al., 1977), and has been characterized previously (NAKAMURA et al., 1991a). For immunohistochemistry, the sections were rinsed three times in KPBS and treated with $0.3 \%$ hydrogen peroxide in $\mathrm{KPBS}$ at $4^{\circ} \mathrm{C}$ overnight to reduce endogenous peroxidase activity. After a rinse in KPBS, the sections were incubated with $0.1 \%$ bovine albumin in KPBS at $4{ }^{\circ} \mathrm{C}$ overnight to avoid non-specific immunoreactivity. They were then incubated with the ASS antibody at a dilution of 1 : 1000 in KPBS containing $0.3 \%$ Triton X-100, $0.3 \%$ bovine serum albumin, $1 \%$ normal goat serum, and $0.2 \%$ sodium azide for 5 days at $4^{\circ} \mathrm{C}$. After rinsing three times for $10 \mathrm{~min}$ in KPBS, the sections were incubated in biotinylated goat anti-rabbit IgG (Vector Labs, Burlingame, CA) at a dilution of $1: 500$ in KPBS containing $0.3 \%$ Triton X-100, $0.3 \%$ bovine serum albumin, $1 \%$ normal goat serum and $0.2 \%$ sodium azide at $4^{\circ} \mathrm{C}$ overnight. They were then washed and incubated in $1 \%$ avidine-biotinylated horseradish peroxidase complex (ABC Elite-kit, Vector Labs, Burlingame, CA) in KPBS containing $0.3 \%$ bovine serum albumin for $2 \mathrm{~h}$. The sections were washed in KPBS, rinsed in $0.1 \mathrm{M}$ acetate buffer $(\mathrm{pH} 6.0)$ three times for $15 \mathrm{~min}$, and incubated in a 
reaction solution containing $0.05 \% 3,3^{\prime}$-diamidinobenzidine tetrahydrochloride (DAB), 2.5\% nickel ammonium sulfate, $0.25 \% \beta$-D-glucose, $0.04 \%$ ammonium chloride, and 6 units of glucose oxidase (Toyobo, Tokyo) in $100 \mathrm{ml}$ of $0.1 \mathrm{M}$ acetate buffer (pH 6.0) for $2-4 \mathrm{~h}$ at $4^{\circ} \mathrm{C}$. They were finally washed, mounted on gelatinized slides, dried, cleared with xylene, and coverslipped with Canada balsam.

\section{Double-labeling immunohistochemistry of ASS and NOS}

The sections were soaked with $0.1 \%$ bovine albumin in $\mathrm{KPBS}$ at $4^{\circ} \mathrm{C}$ overnight, and then incubated with the rabbit antibody to ASS at a dilution of $1: 1000$ in KPBS containing $0.3 \%$ Triton X-100, $0.3 \%$ bovine serum albumin, $1 \%$ normal goat serum, and $0.2 \%$ sodium azide for 5 days at $4^{\circ} \mathrm{C}$. After rinsing three times for $10 \mathrm{~min}$ in KPBS, the sections were incubated in FITC-conjugated affinity purified goat antirabbit IgG (Vector Labs, Burlingame, CA) at a dilution of 1: 200 in KPBS overnight at $4^{\circ} \mathrm{C}$ and were then washed in KPBS three times for $10 \mathrm{~min}$. Thereafter, for double-labeling immunohistochemistry, the sections were incubated in sheep antitserum raised against rat brain NOS (HERBISON et al., 1996) at a dilution of $1: 5000$ in KPBS containing $0.3 \%$ Triton $\mathrm{X}-100,0.3 \%$ bovine serum albumin, $1 \%$ normal goat serum, and $0.2 \%$ sodium azide for 5 days at $4{ }^{\circ} \mathrm{C}$. After rinsing three times for $10 \mathrm{~min}$ in KPBS, the sections were incubated in biotinylated rabbit anti-sheep IgG (Vector Labs) at a dilution of $1: 200$ in KPBS overnight at $4^{\circ} \mathrm{C}$ and were then washed in KPBS three times for $10 \mathrm{~min}$. They were then incubated in Texas Red-streptavidin (Vector Labs) at a dilution of $1: 200$ in KPBS overnight at $4^{\circ} \mathrm{C}$. The sections were washed in KPBS three times for 10 min, mounted on gelatinized slides and covered with Vectashield (Vector Labs).

\section{Data analysis}

\section{Schematic drawings}

We observed Nissl staining sections under a light microscope to analyse the hypothalamic structure and to distinguish the boundary of each region of the hypothalamus. The nomenclature of each region and stereotaxic planes were adapted to the atlas by BERMAN and JONES (1982). Because there were no differences in the distribution pattern of four animals in NADPH-d histochemistry and ASS immunohistochemistry, we observed representative sections from one animal to draw maps of the hypothalamus with semiquantitative analysis of the number of the neu- rons (Fig. 1) under a light microscope equipped with camera lucida.

\section{Confocal laser scanning microscopy}

For observation of double-labeled preparations, we used the dual wavelength configuration of the LSMGB 200 confocal laser scanning microscope (Olympus, Tokyo). This configuration uses a $488 \mathrm{~nm}$ excitation wavelength to detect FITC-emitted fluorescence as green, and a $568 \mathrm{~nm}$ excitation wavelength to detect Texas Red-emitted fluorescence as red. We carefully verified in advance that no detectable cross talk signals of the other fluorescence dye were recognized in each experiment. Serial optical sections at intervals of $1.5 \mu \mathrm{m}$ were projected on a single plane extending for $10-20 \mu \mathrm{m}$ in thickness (volume projection method). Green and red images acquired simultaneously were either presented separately or as a superimposed image to reveal the distribution of double-labeled neurons that appeared yellow. Occasionally, some yellow images were obtained by the overlap of ASS single-immunopositive (green) and NOS single-immunopositive (red) neurons. We confirmed the overlapping by the observation of serial optical sections.

\section{Measurements of neurons}

In NADPH-d histochemistry, ASS immunohistochemistry and double-labeling immunohistochemistry of ASS and NOS, the long axis of neuronal profiles with NADPH-d activity, ASS-immunoreactivity and NOSimmunoreactivity were measured in every fifth section of each region of the unilateral hypothalamus from all eight animals under the light microscope and confocal laser scanning microscope. As in the doublelabeling immunohistochemistry of ASS and NOS observed with laser scanning microscope, fragments of neurons were occasionally obtained. Neurons with visible full nuclei were included in the measurements, and the fragments of cells were excluded. Also, as in NADPH-d histochemistry and ASS immunohistochemistry visualized with nickel enhanced $\mathrm{DAB}$, the nuclei were not visible clearly, so that neurons with visible full somal volume were included in the measurements, and the fragments of cells were excluded. For the description of the neuron size, we used the terms "small" when the long axis of neuron was less than $10 \mu \mathrm{m}$, "medium" when the long axis was $11-30$ $\mu \mathrm{m}$, and "large" when it was over $31 \mu \mathrm{m}$.

\section{Counting of double-labeled neurons}

For calculations of the double-labeled neurons in the double-labeling immunohistochemistry of ASS and NOS, the number of neuronal profiles with ASS- 
immunoreactivity, NOS-immunoreactivity and ASS/ NOS double-labeling was counted separately in every third section of each region of the unilateral hypothalamus from four animals under the confocal laser scanning microscope. In the counting of double-labeled neurons, only neuronal profiles completely doublelabeled were included in the counts, while the images obtained by the overlapping neurons were excluded. The ratio of double-labeled neurons to ASS-immunoreactive neurons or NOS-immunoreactive neurons were expressed as mean \pm standard deviations (S.D.) (Table 2).

\section{Preparation of photos and figures}

We prepared the photos and figures of the ASS-immunoreactive and NADPH-d positive images with a digital camera and printer system. For photographing, we obtained digital images using a FUJIX HC 2000 (Fuji, Tokyo) equipped with a Nikon Optiphoto (Nikon, Tokyo). The digital images were assembled and labeled without processing, and were printed with Fuji Pictrography 3000 (Fuji). To prepare confocal laser scanning microscope photos and figures, simultaneously acquired FITC and Texas Red fluorescent images were superimposed and printed with Fuji Pictrography 3000 (Fuji).

\section{RESULTS}

In the ASS and NOS immunohistochemistry, when the primary antibody, the secondary antibody, or tertiary reagents from the protocol were removed, there were no immunohistochemical labelings of the tissue.
In the anterior hypothalamic area, medium-sized, bipolar and triangular or oval-shaped neurons were NADPH-d positive (Figs. 1A, B, 2A). Neurons with similar size and shape were also ASS-immunoreactive (Fig. 2B). We found NADPH-d positive and ASS-immunoreactive fibers in this region as well. Double-labeled neurons were found here (Fig. 6A). These neurons were medium-sized and oval in shape. Double-labeled neurons represented $30.4 \pm 7.6 \%$ of the ASS-immunoreactive neurons and $19.0 \pm 2.2 \%$ of the NOS-immunoreactive neurons.

In the anterior hypothalamic nucleus, small to medium-sized, oval-shaped neurons were NADPH-d positive and weakly ASS-immunoreactive (Figs. 1D, $2 \mathrm{C}, \mathrm{D})$. We could not recognize any double-labeled neurons here. ASS-immunoreactive and NADPH-d positive fibers were found in the region between the ventral part of the nucleus and the anterior part of the paraventricular nucleus of the hypothalamus (Fig. 2E. F).

In the paraventricular nucleus of the hypothalamus, a large number of medium to large-sized multipolar neurons were NADPH-d positive (Fig. 3A). Also, a number of multipolar neurons with 3-5 cell processes were NADPH-d positive (Fig. 3A). NADPH-d positive and ASS-immunoreactive neurons were differentially distributed here: NADPH-d positive neurons were localized in the lateral part of the nucleus, whereas ASS-immunoreactive neurons were localized in the medial part. Double-labeled neurons were localized in the transitional zone at the boundary between the medial and the lateral part of the nucleus (Fig. 6B). They were medium-sized and triangular or oval in shape, and comprised $22.6 \pm 6.1 \%$ of the ASS-immunoreactive neurons and $26.3 \pm 3.8 \%$ of the NOS-immunoreactive neurons.

Fig. 1 A-H. Semischematic drawings of the distributions of nicotinamide adenine dinucleotide phosphatediaphorase (NADPH-d) positive (open triangles in the left half of the drawings) and argininosuccinate synthetase-immunoreactive (dots in the right half of the drawings) neurons in the hypothalamus. One triangle represents $5 \mathrm{NADPH}$-d positive neurons, and one dot represents 5 ASS-immunoreactive neurons. Coronal sections are arranged from rostal (A, A16.4) to caudal (H, A8.3).

Abbreviations: $A C$ anterior commissure, $A C C$ nucleus accumbens, $A C N$ nucleus of anterior commissure, $A H$ anterior hypothalamic nucleus, $C A$ caudate nucleus, $D B$ diagonal band of Broca, $D B H$ diagonal band of Broca, horizontal division; $D H$ dorsal hypothalamic nucleus, $D M H$ dorsomedial hypothalamic nucleus, $F$ founix, $F F$ nucleus of the fields of Forel, $H A A$ anterior hypothalamic area, $H D A$ dorsal hypothalamic area, $H L A$ lateral hypothalamic area, HPA posterior hypothalamic area, $I C$ internal capsule, $I N F$ infundibular nucleus, $I S C$ island of Calleja, $L V$ lateral ventricle, $M M$ mammillary body, $M S$ supramammillary nucleus, $M T$ mammillothalamic tract, $O C$ optic chiasma, $O T$ optic tract, $P A H$ paraventricular nucleus of the hypothalamus, $P A R A$ anterior paraventricular nucleus of the thalamus, $P A T$ parataenial nucleus, $P E H$ periventricular complex, $P P$ pes peduncli, $P V H$ parvocellular hypothalamic nucleus, $S C N$ suprachiasmatic nucleus, $S I$ substantia innominata, SMN medial septal nucleus, SON supraoptic nucleus, SPF subparafascicular nucleus, $S T$ nucleus of the stria terminalis, $S T N$ triangular septal nucleus, $S U B$ subthalamic nucleus, $T C A$ area of the tuber cinereum, $V M B$ basal ventromedial nucleus of the thalamus, $V M H$ ventromedial hypothalamic nucleus, $V 3$ third ventricle, $Z I$ nucleus of the zone incerta. 

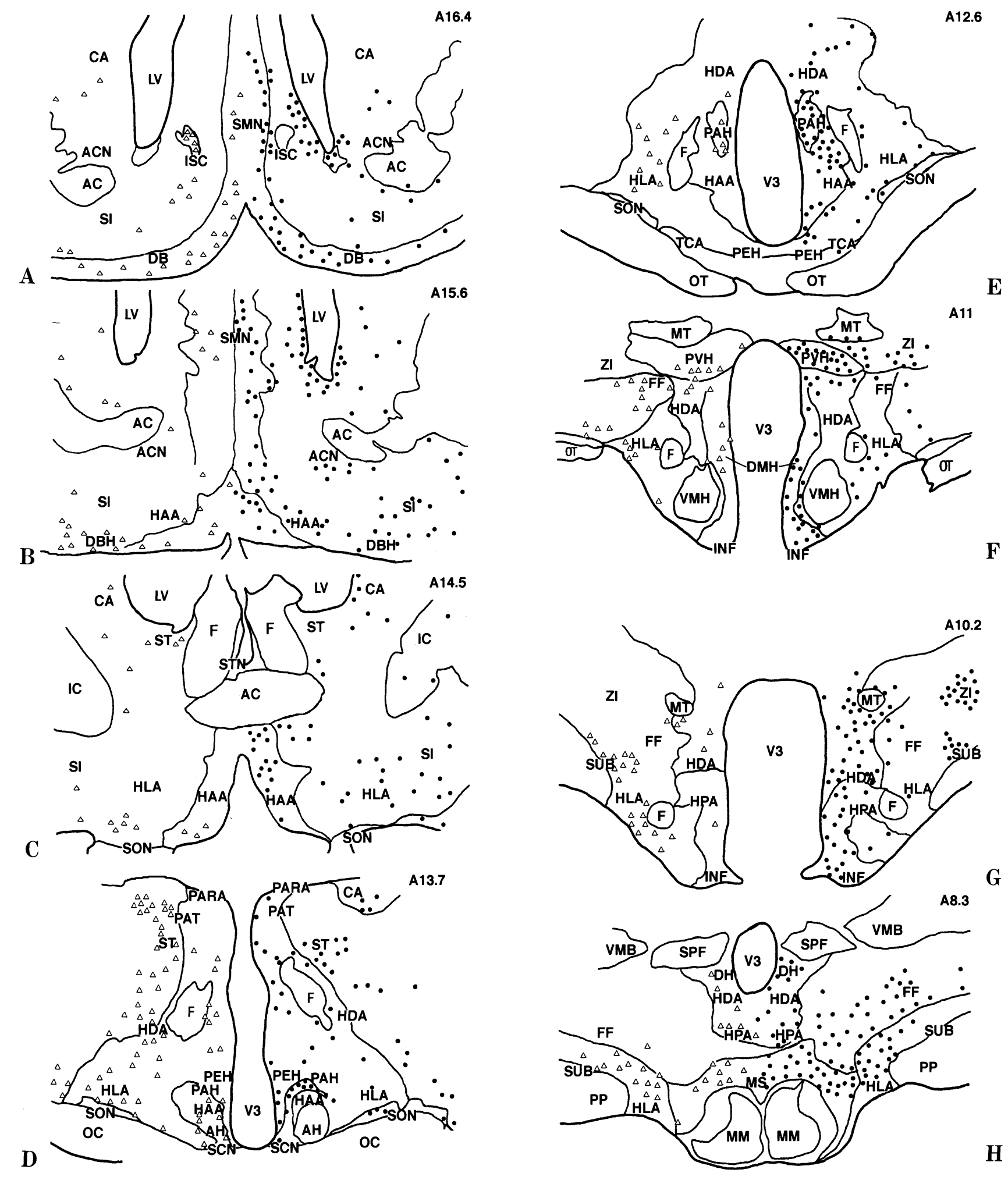

Fig. 1. Legend on the opposite page. 
A
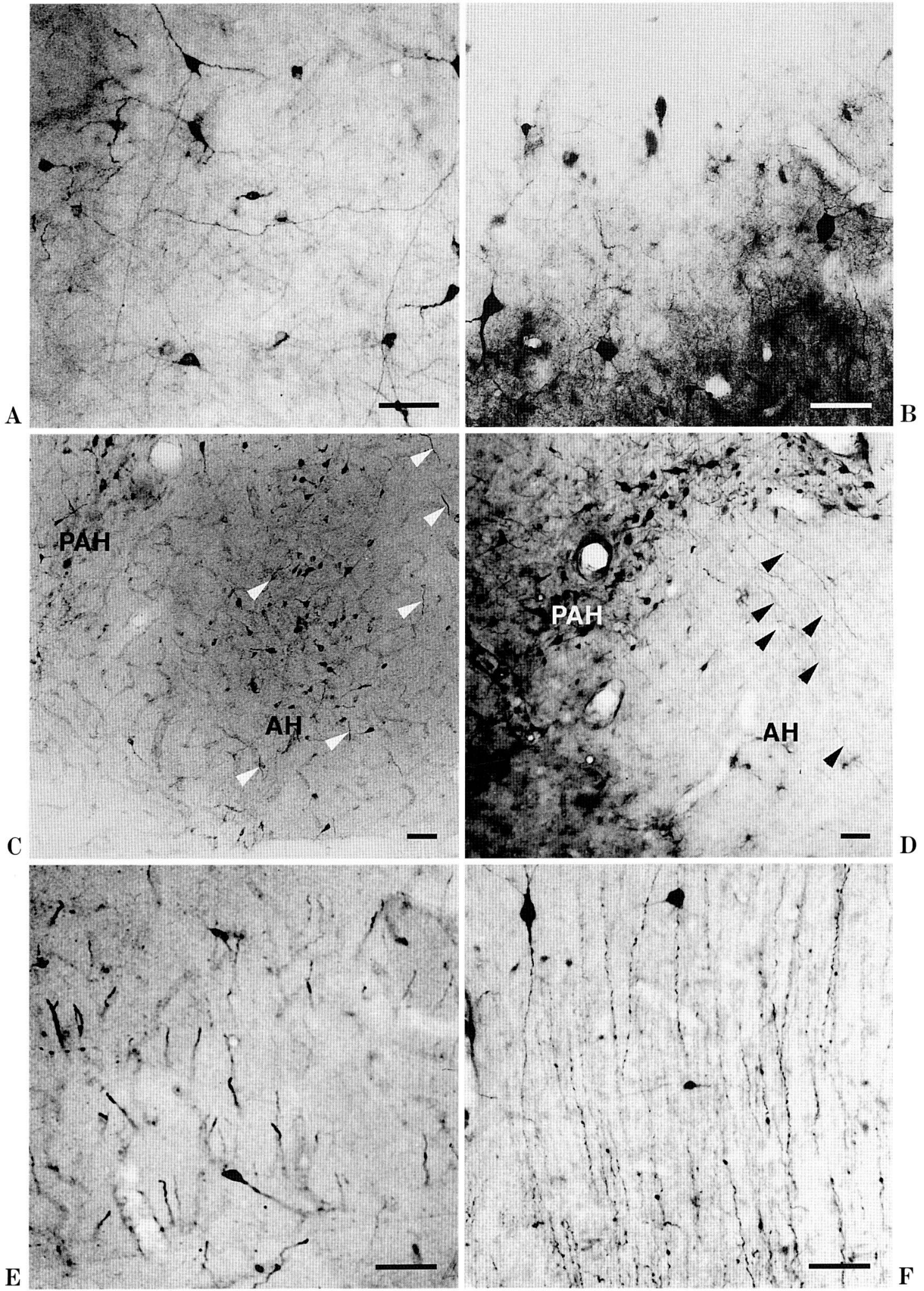

Fig. 2 A and B. NADPH-d positive (A) and ASS-immunoreactive (B) neurons in the anterior hypothalamic area. $\mathbf{C}-\mathbf{F}$ (serial sections). NADPH-d positive (C, E) and ASS-immunoreactive (D, F) neurons and fibers (white arrowheads in $\mathbf{C}$, black arrowheads in $\mathbf{D}$ ) in the anterior hypothalamic nucleus. Left part of the figures is medial. Scale bars $=50 \mu \mathrm{m}$. 


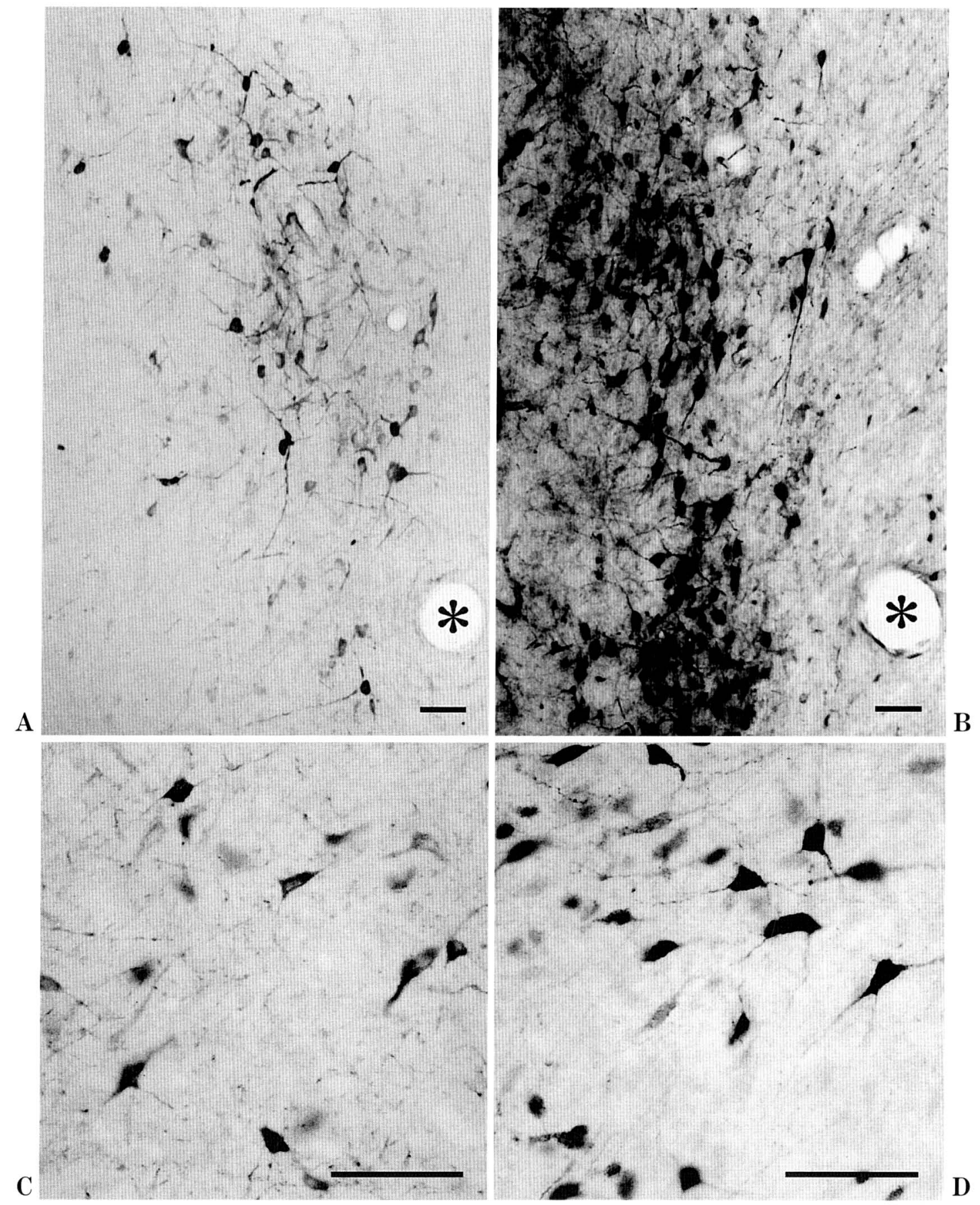

Fig. 3. A and B (serial sections). NADPH-d positive (A) and ASS-immunoreactive (B) neurons in the paraventricular nucleus of the hypothalamus. Asterisks in $\mathbf{A}$ and $\mathbf{B}$ indicate the same blood vessel. Left part of the figures is medial. Scale bars $=50 \mu \mathrm{m}$. C and D. NADPH-d positive (C) and ASS-immunoreactive (D) neurons in the parvocellular hypothalamic nucleus. Right part of the figures is medial. Scale bars $=100 \mu \mathrm{m}$. 


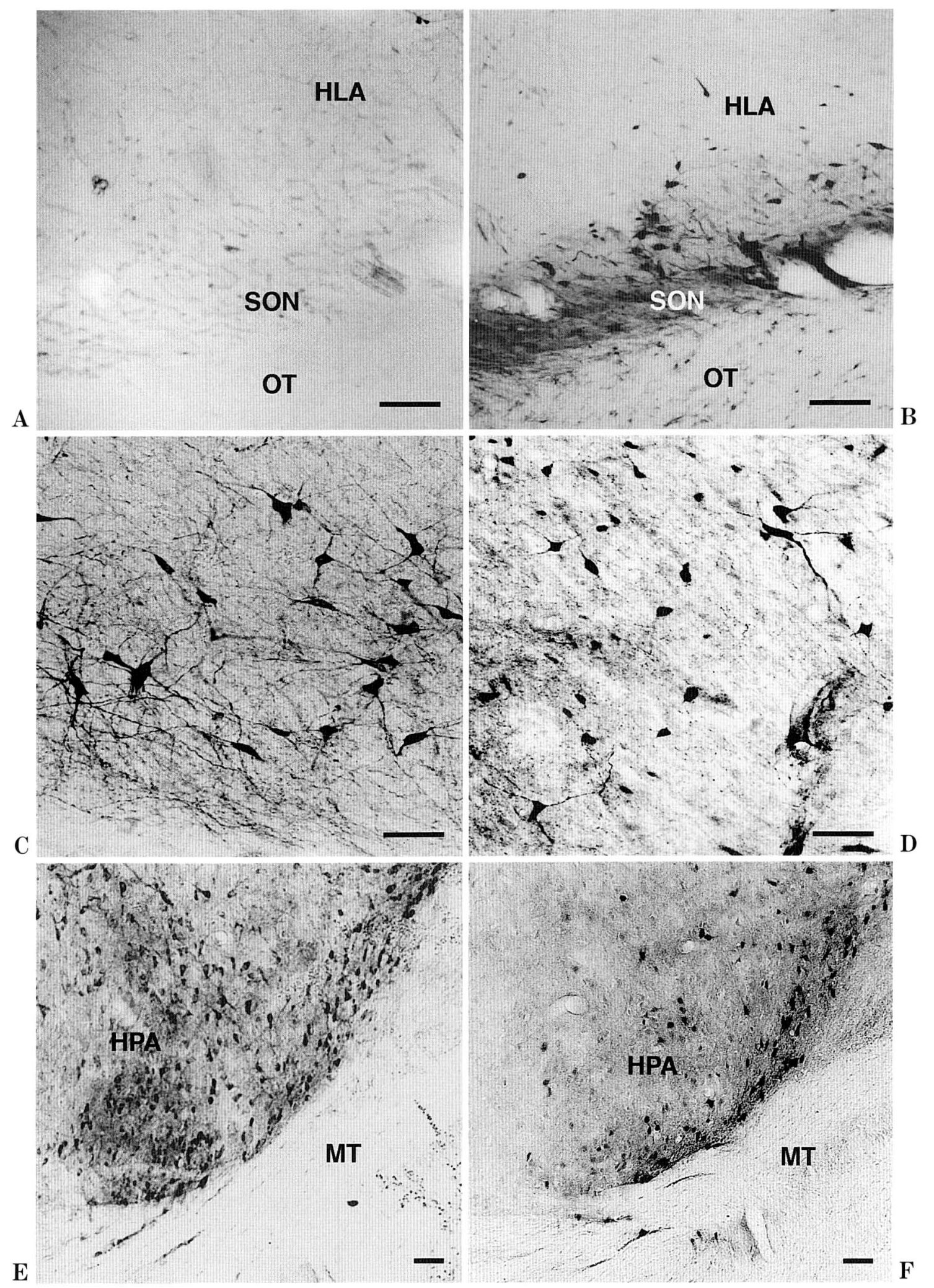

Fig. 4. A and B (serial sections). Faint NADPH-d positive (A) and ASS-immunoreactive neurons (B) in the supraoptic nucleus and the lateral hypothalamic area. Left part of the figures is medial. Scale bars $=100 \mu \mathrm{m}$. C and D. NADPH-d positive (C) and ASS-immunoreactive (D) neurons in the anterior part of the lateral hypothalamic area. Right part of the figures is medial. $\mathbf{E}$ and $\mathbf{F}$ (serial sections). NADPH-d positive (E) and ASS-immunoreactive $(\mathbf{F})$ neurons in the posterior hypothalamic area. Left part of the figures is medial. Scale bars $=50 \mu \mathrm{m}$. 


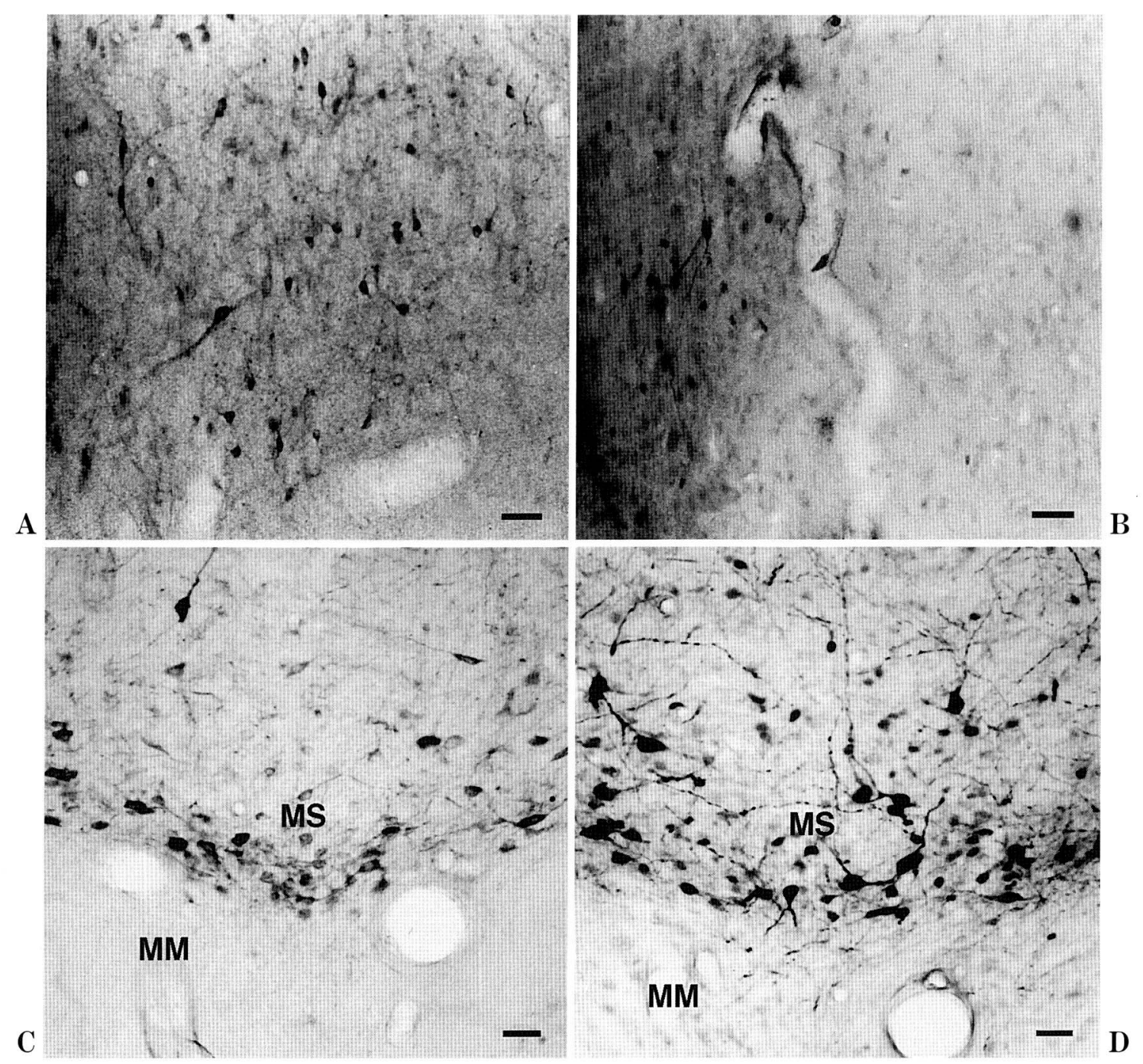

Fig. $5 \mathbf{A}$ and $\mathbf{B}$ (serial sections). NADPH-d positive (A) and ASS-immunoreactive (B) neurons in the dorsomedial hypothalamic nucleus. Left part of the figures is medial. C and D (serial sections). NADPH-d positive (C) and ASS-immunoreactive (D) neurons in the supramammillary nucleus. Scale bars $=50 \mu \mathrm{m}$.

A few NADPH-d positive neurons were found in the ventral part of the parvocellular hypothalamic nucleus (Fig. 1F). The neurons were small to mediumsized, oval and triangular in shape, and had very short processes (Fig. 3C). A number of neurons were also ASS-immunoreactive throughout the nucleus, their size and shape being similar to the NADPH-d positive neurons (Fig. 3D). Double-labeled neurons were localized in the ventral part of the distribution of ASS-immunoreactive neurons and in the dorsal part of that of the NOS-immunoreactive neurons. These comprised $32.0 \pm 4.9 \%$ of the ASS-immunoreactive neurons and $15.0 \pm 3.0 \%$ of the NOS-immunoreactive neurons.
In the supraoptic nucleus, many neurons were NADPH-d positive in its caudal part located lateral to the optic tract, whereas in the rostral part of its dorsal neurons were only weakly NADPH-d positive (Figs. 1D, 4A). Several ASS-immunoreactive neurons were observed mostly in the rostral region dorsal to the optic tract (Fig. 1D). They were small-sized and oval in shape (Fig. 4B). Double-labeled neurons were found in the rostral region dorsal to the optic tract, and were also small-sized and oval in shape. They represented $23.5 \pm 5.2 \%$ of the ASS-immunoreactive neurons and $17.5 \pm 3.6 \%$ of the NOS-immunoreactive neurons.

In the suprachiasmatic nucleus, small to medium- 

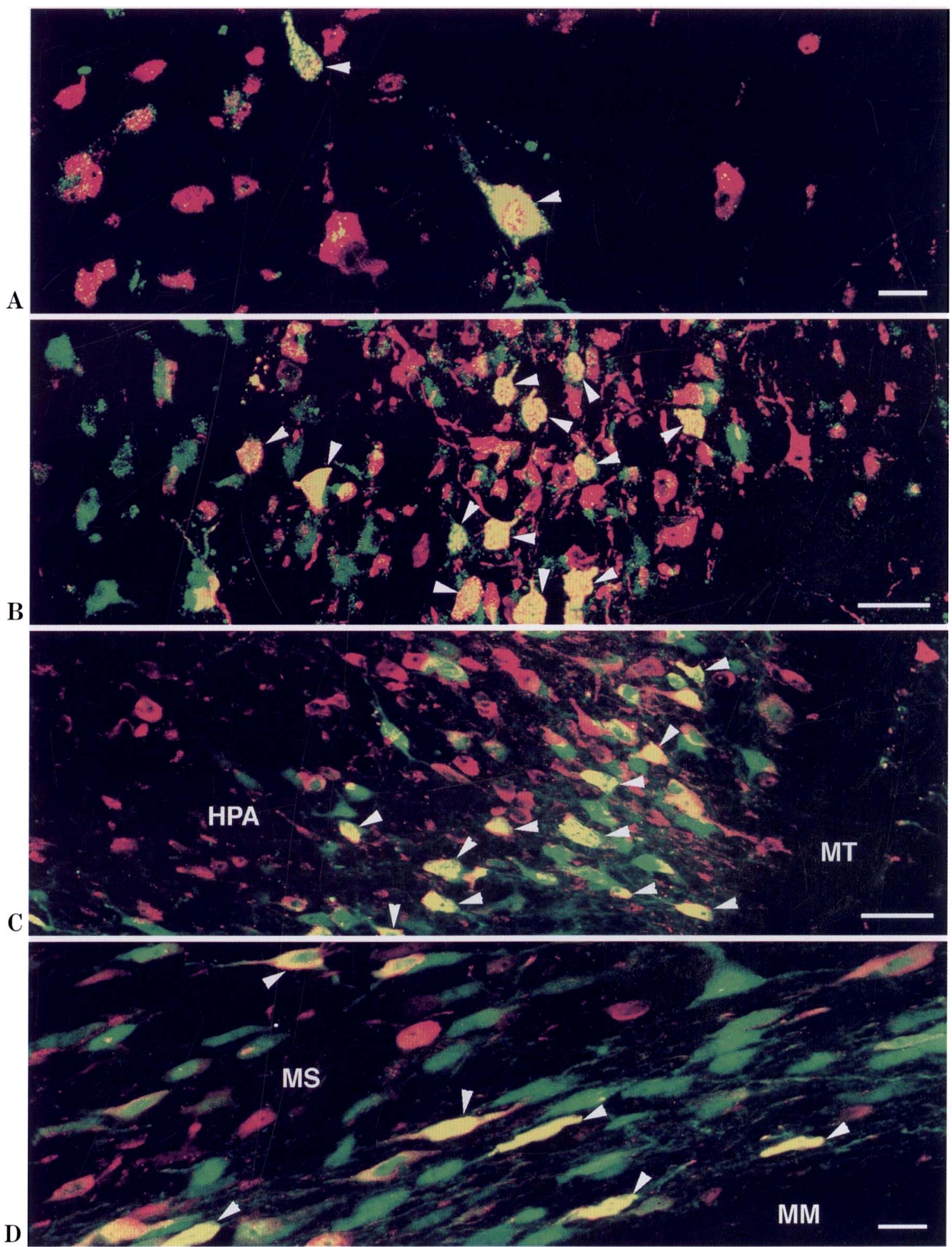

Fig. 6 A-D. Confocal laser scanning microscope illustration showing ASS-immunoreactive (green), NOS-immunoreactive (red) and double-labeled (yellow) neurons in the anterior hypothalamic area (A), the paraventricular nucleus of the hypothalamus (B), the posterior hypothalamic area (C), and the supramammillary nucleus (D). Green and red images were obtained simultaneously and superimposed to show double-labeled neurons that appear yellow. Double-labeled neurons are indicated by arrowheads. Left part of the figures is medial. Scale bars $=20 \mu \mathrm{m}$. 
sized, oval-shaped neurons were NADPH-d positive. Similar neurons were also found to be ASS-immunoreactive; however, we could not detect any doublelabeled neurons in this region.

In the rostral and middle region of the lateral hypothalamic area, medium to large-sized multipolar neurons with 3-5 long processes were strongly NADPH-d positive (Figs. 1C-H, 4C). ASS-immunoreactive neurons in this region were medium to largesized, bipolar and multipolar cells (Fig. 4D). In the caudal region of the lateral hypothalamic area, a few small neurons were NADPH-d positive and ASSimmunoreactive. Double-labeled neurons were found in the rostral and middle region of the area. They were medium-sized, bipolar and multipolar in shape, and occupied $29.1 \pm 8.7 \%$ of the ASS-immunoreactive neurons and $10.2 \pm 2.8 \%$ of the NOS-immunoreactive neurons. Many NADPH-positive fibers were observed between this region and the dorsal hypothalamic area.

Table 1. Distribution summary of ASS-immunoreactive/NADPH-d positive neurons in the hypothalamus.

\begin{tabular}{|c|c|c|c|c|}
\hline \multirow{2}{*}{ Structure } & \multicolumn{2}{|c|}{ NADPH-d } & \multicolumn{2}{|c|}{ ASS } \\
\hline & Neurons & Fibers & Neurons & Fibers \\
\hline Anterior hypothalamic area & ++ & - & ++ & - \\
\hline Anterior hypothalamic nucleus & + & ++ & + & ++ \\
\hline \multicolumn{5}{|l|}{ Supraoptic nucleus } \\
\hline dorsal part & - & - & + & - \\
\hline lateral part & ++ & + & + & - \\
\hline Suprachiasmatic nucleus & + & + & + & - \\
\hline Periventricular complex & ++ & ++ & ++ & ++ \\
\hline \multicolumn{5}{|l|}{ Paraventricular nucleus } \\
\hline medial part & + & - & +++ & + \\
\hline lateral part & +++ & + & + & - \\
\hline Parvocellular nucleus & +++ & - & +++ & - \\
\hline Lateral hypothalamic area & +++ & + & +++ & + \\
\hline \multicolumn{5}{|l|}{ Dorsomedial nucleus } \\
\hline medial part & + & - & ++ & - \\
\hline lateral part & ++ & - & - & - \\
\hline Dorsal hypothalamic area & ++ & + & ++ & - \\
\hline Ventromedial nucleus & - & + & - & - \\
\hline Posterior hypothalamic area & +++ & + & +++ & + \\
\hline Supramamillary nucleus & +++ & + & +++ & + \\
\hline Lateral mamillary nucleus & - & - & ++ & + \\
\hline
\end{tabular}

Numbers of + indicate density of neurons and fibers. +++ , numeronus (over $200) ;++$, moderate $(50-200) ;+$, rare (under 50$) ;-$, not detected.

Table 2. Numbers of neurons and percentages (mean \pm S.D.) of coexistence of NOS-immunoreactive and ASS-immunoreactive in the hypothalamus (number of animals=4).

\begin{tabular}{lccccc}
\hline Structure & ASS & NOS & Double-labeled & $\% /$ ASS & $\% /$ NOS \\
\hline Anterior hypothalamic area & $75 \pm 4.6$ & $121 \pm 19.7$ & $23 \pm 3.3$ & $30.4 \pm 7.6$ & $19.0 \pm 2.2$ \\
Supraoptic nucleus & $90 \pm 8.1$ & $120 \pm 13.6$ & $20 \pm 3.0$ & $23.5 \pm 5.2$ & $17.5 \pm 3.6$ \\
Paraventricular nucleus & $469 \pm 20.8$ & $407 \pm 40.4$ & $106 \pm 13.7$ & $22.6 \pm 6.1$ & $26.3 \pm 3.8$ \\
Parvocellular nucleus & $350 \pm 61.5$ & $765 \pm 186.3$ & $110 \pm 5.7$ & $32.0 \pm 4.9$ & $15.0 \pm 3.0$ \\
Lateral hypothalamic area & $378 \pm 5.3$ & $665 \pm 157.5$ & $65 \pm 11.6$ & $29.1 \pm 8.7$ & $10.2 \pm 2.8$ \\
Posterior hypothalamic area & $313 \pm 39.5$ & $495 \pm 52.5$ & $78 \pm 10.3$ & $24.9 \pm 9.4$ & $15.9 \pm 2.7$ \\
Supramamillary nucleus & $264 \pm 31.4$ & $229 \pm 27.1$ & $54 \pm 6.1$ & $20.7 \pm 3.4$ & $21.2 \pm 9.1$ \\
\hline
\end{tabular}


In the posterior hypothalamic area, many mediumsized, oval and triangular neurons were NADPH-d positive (Fig. 4E). Similar neurons were also ASSimmunoreactive (Fig. 4F). Double-labeled neurons for ASS and NOS were medium-sized and triangular in shape, comprising $24.9 \pm 9.4 \%$ of the ASS-immunoreactive neurons and $15.9 \pm 2.7 \%$ of the NOS-immunoreactive neurons (Fig. $6 \mathrm{C}$ ).

In the dorsal hypothalamic area, medium-sized, bipolar and multipolar neurons were NADPH-d positive and ASS-immunoreactive, and were localized mainly in the posterior part (Fig. 1D-H). No doublelabeled neurons were detected in this area. Neither NADPH-d positive nor ASS-immunoreactive neurons appeared in the ventromedial nucleus. Faint NADPH-d positive fibers were seen in the central part of the nucleus.

In the dorsomedial hypothalamic nucleus, NADPH-d positive neurons were small-sized and oval in shape, and located in the lateral part of the nucleus (Figs. $1 \mathrm{~F}, 5 \mathrm{~A}$ ), whereas in the medial part of the nucleus, small-sized, oval and bipolar neurons were ASS-immunoreactive (Figs. 1F, 5B). The medio-lateral segregation of NADPH-d positive and ASS-immunoreactive neurons was the same as that seen in the paraventricular nucleus of the hypothalamus. We did not detect any double-labeled neurons in this nucleus.

In the supramammillary nucleus, many medium to large, bipolar and multipolar neurons were NADPHd positive and ASS-immunoreactive. NADPH-d positive neurons were mainly localized in the ventral region of the nucleus, whereas ASS-immunoreactive neurons were scattered throughout the nucleus. NADPH-d positive fibers were sparse, whereas many ASS-immunoreactive fibers were found within the nucleus (Figs. 1H, 5C, D). Many medium to largesized, spindle-shaped double-labeled neurons were frequently found in the region dorsolateral to the mammillary body (Fig. 6D). Double-labeled neurons comprised $20.7 \pm 3.4 \%$ of the ASS-immunoreactive neurons and $21.2 \pm 9.1 \%$ of the NOS-immunoreactive neurons.

\section{DISCUSSION}

We have mapped the detailed distribution of ASSimmunoreactive and NADPH-d positive neurons and found the co-localization of ASS and NOS in the several regions of the cat hypothalamus.

\section{ASS immunohistochemistry}

Our study used a rabbit antibody raised against purified rat liver ASS. This antiserum for ASS detected a $45 \mathrm{kDa}$ protein as a single band in Western blot analysis of rat liver homogenate (NAKAMURA et al., 1991a), which fits the molecular weight of the ASS subunit mass. The nucleotide sequences of the cDNA encoding the ASS of the mouse, rat, bovine and human were almost identical (Bock et al., 1983; SURH et al., 1988, 1991; DENNIS et al., 1989; KoBAYASHI et al., 1990). Therefore it seems reasonable to consider that ASS has an almost identical structure amongst mammalian species, and thus our antibody against rat liver ASS detected cat brain ASS.

We have confirmed ASS-immunoreactive neurons in many regions of the hypothalamus (Table 1). In a study of the rat (ARNT-RAMOS et al., 1992), ASSimmunoreactive neurons were detected in the anterior hypothalamic area, the lateral hypothalamic area, and the supramammilaly nucleus. We confirmed ASS-immunoreactive neurons in these areas in the cat hypothalamus. Further, we found ASS-immunoreactive neurons in more regions compared with results in the rat (ARNT-RAMOS et al., 1992): the paraventricular nucleus of the hypothalamus, the parvocellular hypothalamic nucleus, the supraoptic nucleus, the suprachiasmatic nucleus, the dorsal hypothalamic area, the dorsomedial hypothalamic nucleus and the posterior hypothalamic area. There are some possibilities to explain this discrepancy, one is the technical difference. We used an antibody raised against rat liver ASS, but ARNT-RAMOS et al. used an antibody raised against human brain ASS. Another possibility is the species difference.

Most of the ASS-immunoreactive neurons we observed in this study were small to medium in size and had short processes, so that they seem to be interneurons as suggested by NAKAMURA et al. (1991a). Moreover, we have also recognized that in the paraventricular nucleus of the hypotalamus, ASS-immunoreactive neurons were distributed in the medial part, the neurons of which may act as relay or interneuronal pool, since axons of the smaller medial cells terminate on dendrites of the larger lateral cells (VAN DEN POL, 1982). Thus, ASS-immunoreactive neurons may be interneurons in the cat hypothalamus.

\section{NADPH-d histochemistry}

In this study we observed NADPH-d positive neurons in many regions of the cat hypothalamus (Table 1). MizuKAWA et al. (1989) have detected NADPH-d positive neurons in the anterior hypothalamic area, the supraoptic nucleus, paraventricular hypothalamic nucleus, the lateral hypothalamic area, the dorsal 
hypothalamic area and the posterior hypothalamic area of the cat. We confirmed NADPH-d positive neurons in these areas. Further, we found NADPH-d positive neurons in the dorsomedial hypothalamic nucleus and the supramammillary nucleus. In a study of the rat (VINCENT and KimURA, 1992; YAMADA et al., 1996), NADPH-d positive/NOS-immunoreactive neurons were detected in the anterior hypothalamic area, the supraoptic nucleus, paraventricular hypothalamic nucleus, the lateral hypothalamic area, the ventrolateral region of the ventromedial nucleus, the dorsal hypothalamic area, the dorsomedial hypothalamic nucleus, the posterior hypothalamic area and the supramammillary nuclues. Compared with these results from the rat, one difference in our study was that NADPH-d positive neurons in the ventrolateral region of the ventromedial nucleus were not recognized.

\section{Mediolateral differences in the paraventricular and dorsomedial nuclei}

In the lateral part of the 'PVN/DMH complex' (paraventricular nucleus/dorsomedial hypothalamic nucleus) (KALSBEEK et al., 1992), we confirmed the localization of NADPH-d positive neurons (ARÉVALO et al., 1992; CALKA and Block, 1993; MiYAGAWA et al., 1994; MURAKAMI, 1994; SiAUD et al., 1994 YAMADA et al., 1996). On the other hand, we found ASSimmunoreactive neurons in the medial part of 'PVN/ DMH complex'. The medial part of paraventricular nucleus was characterized by the presence of a large number of neurons containing releasing factors and releasing inhibitory factors modulating the secretion of prolactine, growth hormone, luteinizing hormone, follicle stimulating hormone, thyroid stimulating hormone and adrenocorticotropic hormone (BJÖRKLUND, 1987; LUITEN et al., 1987). VAN DEN POL et al. (1990) indicated that the neurons in the PVN respond to glutamate, quisqualate, kinate with a consistent increase in intracellular calcium, but not to N-methylD-aspartate (NMDA). Argininosuccinate, the product of ASS, is suggested to play a neuromodulational function by decreasing glutamate and quisqualate responses but to have no effect in the kinate and NMDA receptors (NAKAMURA et al., 1991b). From this point of view, we hypothesize that argininosuccinate may modulate the neuronal functions in the medial part of the 'PVN/DMH complex' via regulation of glutamate receptors. Further, NO may increase inhibitory postsynaptic potentials by activating GABAergic neurons modulating the neuroendocrine function in PVN (BAINS and FERGUSON, 1997a). It is also reported that NO depolarizes neurons in the medial regions of $\mathrm{PVN}$ in which ASS exsis abundantly, through a mechanism that is dependent upon activation of cGMP (BAINS and FERGUSON, 1997b). Thus, the distribution pattern of ASS/NOS-immunoreactive neurons in PVN in our study suggests that argininosuccinate and NO may modulate the neuroendocrine functions through the glutamate/GABA system.

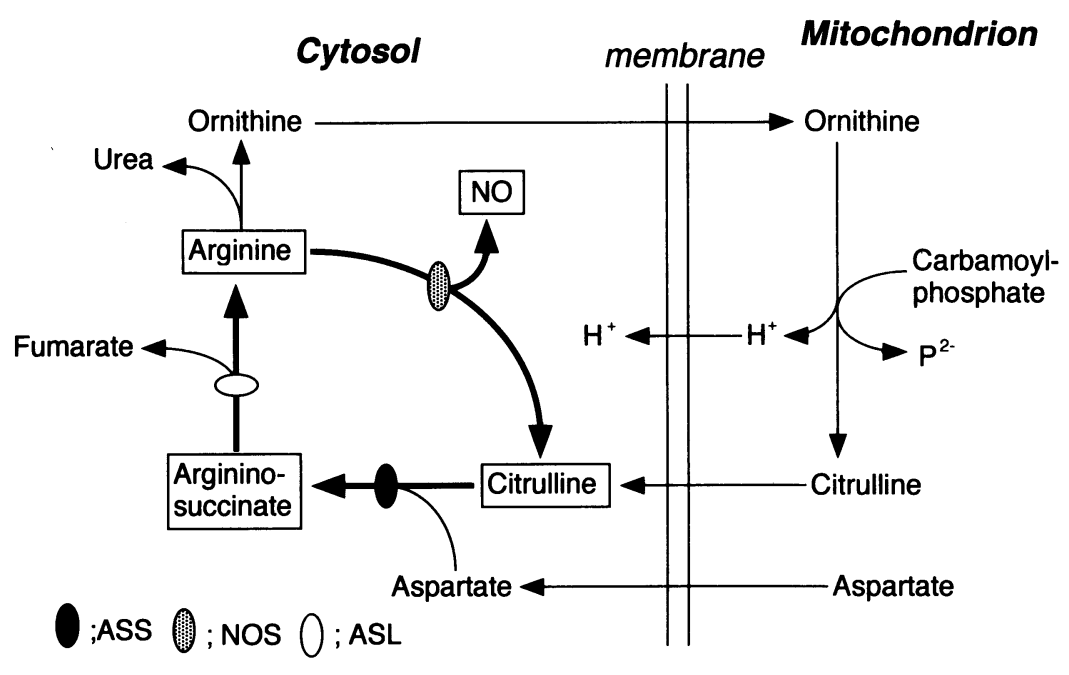

Fig. 7. Schematic diagram of the urea cycle and the 'NO cycle' (thick lines). ASL argininosuccinate lyase, ASS argininosuccinate synthatase, $N O$ nitric oxide, NOS nitric oxide synthase. 


\section{Co-localization of ASS and NOS}

For the double-labeling study we used double immunohistochemistry using two specific antibodies, a more reliable method than the double staining of ASS immunohistochemistry and NADPH-d histochemistry. We were able to observe fluorescence using confocal laser scanning microscopy. The distribution of NADPH-d positive neurons was in good agreement with that of NOS-immunoreactive neurons. We are first to describe double-labeled neurons in the anterior hypothalamic area, the supraoptic nucleus, central part of the paraventricular nucleus of the hypothalamus, the lateral hypothalamic area, the ventral part of the parvocellular hypothalamic nucleus, the posterior hypothalamic area, and the supramammillary nucleus in the cat hypothalamus (Table 2). The double-labeled neurons were $20.7 \pm 3.4-32.0 \pm 4.9 \%$ of the ASS-immunoreactive neurons and $10.2 \pm 2.8-26.3 \pm 3.8 \%$ of the NOS-immunoreactive neurons. There were more regions with double-labeled neurons in our study than reported in the rat hypothalamus (ARNT-RAMOS et al., 1992). This may be due to the technical differences; we used double-labeling immunohistochemistry of ASS and NOS, while ASS immunohistochemistry and NADPH-d histochemistry were employed in the study of the rat brain (ARNT-RAMOS et al., 1992), although species difference could not be ignored.

The co-localization of ASS and NOS suggests the existence of a cyclic pathway to produce NO (Fig. 7). This cycle is composed of NOS, ASS, and ASL, and could be named 'NO cycle' (NAKAMURA, 1997). In the brain, ASL is localized in glial cells and some neurons; that is, it is ubiquitously distributed. Thus, some regions which include double-labeled neurons may contain the 'NO cycle' and be capable of recycling citrulline to arginine. On the other hand, we found many neurons which contain either ASS or NOS in the cat hypothalamus. The neurons which contain only NOS may be provided with arginine, the precursor of NO, from the surrounding astrocytes (AoKI et al., 1991; Pow, 1994). The citrulline which was produced by NOS neurons lacking ASS, and that may diffuse into the extracellular space without recycling to argininosuccinate in their cytosol. The neurons which contain only ASS may accumulate citrulline from the extracellular space, and the argininosuccinate which is synthesized in these neurons may diffuse into this space.

Several recent reports have indicated the physiological roles of NO in the regions which contain double-labeled neurons. LUPI et al. (1996) suggested that NO generated in the anterior hypothalamic area might be involved in the signal transduction pathway in the suprachiasmatic nucleus. The lateral hypothalamic area, which provides NOergic innervation to the paraventricular thalamic nucleus, may be implicated in food intake and addictive behavior (OTAKE and RUGGIERO, 1995). In the posterior hypothalamus, the inhibition of NOS activity decreases systemic blood pressure (GEROVA et al., 1995). Notably, one of the important functions mediated by these regions is aggressive behavior. Aggressive behavior has been suggested to be modulated in the regions which contain double-labeled neurons (TASHIRO et al., 1985; FERRIS et al., 1997; KOCSIS and VERTES, 1997; OlAZABAL and FERREIRA, 1997; SIEGEL and SHAIKH, 1997). NELSON et al. (1995) reported an increase in aggressive behavior in male mice with the targeted disruption of neuronal NOS. The detailed and precise anatomical relationships of the hypothalamic regions modulating aggresive behavior have not been elucidated, but NO generated in these hypothalamic regions may contribute much to modulate aggressive behavior.

Acknowledgements. The authors wish to thank Dr. Keiichiro NaKamura and Dr. Akio Kuraoka, Department of Anatomy, Kyushu University School of Medicine, for their generous support throughout this study.

\section{REFERENCES}

Aoki, E., R. Semba, K. Mikoshiba and S. Kashiwamata: Predominant localization in glial cells of free L-arginine. Immunocytochemical evidence. Brain Res. 547: 190-192 (1991).

Arévalo, R., F. Sánchez, J. R. Alonso, J. Carretero, R. VÁZquez and J. AIJón: NADPH-diaphorase activity in the hypothalamic magnocellular neurosecretory nuclei of the rat. Brain Res. Bull. 28: 599-603 (1992).

Arnt-Ramos, L. R., W. E. O'Brien and S. R. Vincent: Immunohistochemical localization of argininosuccinate synthetase in the rat brain in relation to nitric oxide synthase-containing neurons. Neuroscience 51: 773-789 (1992).

Bains, J. S. and A. V. Ferguson: Nitric oxide regulated NMDA-driven GABAergic inputs to type I neurons of the rat paraventricular nucleus. J. Physiol. 499: 733-746 (1997a).

: Nitric oxide depolarizes type II paraventricular nucleus neurons in vitro. Neuroscience 79 : 149-159 (1997b).

Benelli, A., A. Bertolini, R. Poggioli, E. Cavazzuti, L. Calza, L. Giardino and R. Arletti: Nitric oxide is involved in male sexual behavior of rats. Eur. J. Pharmacol. 294: 505-510 (1995).

Berman, A. L. and E. G. Jones: The thalamus and the telencephalon of the cat: A cytoarchitectonic atlas with stereotaxic coordinates. University of Wisconsin Press, Madison, 1982. 
BJörkLund, A: The hypothalamus. In: (ed. by) A. BJöRKLUND, T. HökfElT and L. W. Swanson: Handbook of chemical neuroanatomy, Vol. 5. Elsevier, Amsterdam, 1987 (p. 1-124).

Bock, H. G., T. S. Su, W. E. O'Brien and A. L. BeAudeT: Sequence for human argininosuccinate synthetase cDNA. Nucl. Acids Res. 11: 6505-6512 (1983).

BREDT, D. S. and S. H. SNYDER: Isolation of nitric oxide synthetase, a calmodulin-requiring enzyme. Proc. Nat. Acad. Sci. USA 87: 682-685 (1990).

Calapai, G., F. Squadrito, D. Altavilla, B. Zingarelli, G. M. Campo, M. Cilia and A. P. Caputi: Evidence that nitric oxide modulates drinking behavior. Neuropharmacology 31: 761-764 (1992).

CalKa, J. and C. H. Block: Angiotensin- (1-7) and nitric oxide synthase in the hypothalamo-neurohypophysial system. Brain Res. Bull. 30: 677-685 (1993).

Dawson, T. M., D. S. Bredt, M. Fotuhi, P. M. Hwang and S. H. SNYDER: Nitric oxide synthase and neuronal NADPH diaphorase are identical in brain and peripheral tissues. Proc. Nat. Acad. Sci. USA 88: 7797-7801 (1991).

De LuCA, B., M. Monda and A. Sullo: Changes in eating behavior and thermogenic activity following inhibition of nitric oxide formation. Amer. J. Physiol. 268: R15331538 (1995).

Dennis, J. A., P. J. Healy, A. L. Beaudet and W. E. O'Brien: Molecular definition of bovine argininosuccinate synthetase deficiency. Proc. Nat. Acad. Sci. USA 86: 7947-7951 (1989).

Ferris, C. F., R. H. Melloni, Jr., G. Koppel, K. W. Perry, R. W. Fuller and Y. Delville: Vasopressin/ serotonin interactions in the anterior hypothalamus control aggressive behavior in golden hamsters. J. Neurosci. 17: 4331-4340 (1997).

Gerova, M., C. Masanova and J. Pavlasek: Inhibition of NO synthase in the posterior hypothalamus increases blood pressure in the rat. Physiol. Res. 44: 131-134 (1995).

Hattori, Y., E. B. Campbell and S. S. Gross: Argininosuccinate synthetase mRNA and activity are induced by immunostimulants in vascular smooth muscle. Role in the regeneration or arginine for nitric synthesis. J. Biol. Chem. 269: 9405-9408 (1994).

Hecker, M., W. C. Sessa, H. J. Harris, E. E. AngGard and J. R. VANE: The metabolism of L-arginine and its significance for the biosynthesis of endothelium-derived relaxing factor: cultured endothelial cells recycle $\mathrm{L}$ citrulline to L-arginine. Proc. Nat. Acad. Sci. USA 87: 8612-8616 (1990).

Herbison, A. E., S. X. Simonian, P. J. Norris and P. C. EMson: Relationship of neuronal nitric oxide synthase immunoreactivity to $\mathrm{GnRH}$ neurons in the ovariectomized and intact female rat. J. Neuroendocrinol. 8: 73-82 (1996).

Hope, B. T., G. J. MínhaEL, K. M. KNigGe and S. R. VINCENT: Neuronal NADPH diaphorase is a nitric oxide synthase. Proc. Nat. Acad. Sci. USA 88: 28112814 (1991)
KalsbeeK, A., R. M. BuiJs, J. J. VAn Heerikhuize, M. ArTs and T. P. VAN DER Woude: Vasopressin-containing neurons of the suprachiasmatic nuclei inhibit corticosterone release. Brain Res. 580: 62-67 (1992).

Karanth, S., K. Lyson and S. M. McCann: Role of nitric oxide in interleukin 2-induced corticotropinreleasing factor from incubated hypothalami. Proc. Nat. Acad. Sci. USA 90: 3383-3387 (1993).

Kobayashi, K., M. J. Jackson, D. B. Tick, W. E. O'BRIEN and A. L. BEAUdET: Heterogeneity of mutations in argininosuccinate synthetase causing human citrullinemia. J. Biol. Chem. 265: 11361-11367 (1990).

Kocsis, B. and R. P. VerTes: Phase relations of rhythmic neuronal firing in the supramammillary nucleus and mammillary body to the hippocampal theta activity in urethane anesthetized rats. Hippocampus 7: 204-214 (1997).

Luiten, P. G., G. J. Ter Horst and A. B. Steffens: The hypothalamus, intrinsic connections and outflow pathways to the endocrine system in relation to the control of feeding and metabolism. Prog. Neurobiol. 28: 1-54 (1987).

LuPi, D., D. Debernardis, S. Vallerga, P. J. Morgan and M. B. DJAMgoz: NADPH diaphorase activity around the suprachiasmatic nucleus in rat brain. Cell Tiss. Res . 283: 335-338 (1996).

Mitchell, J. A., M. Hecker, E. E. AngGard and J. R. VANE: Cultured endothelial cells maintain their Larginine level despite the continuous release of EDRF. Eur. J. Pharmacol. 182: 573-576 (1990).

Miyagawa, A., H. OKamura and Y. Ibata: Coexistence of oxytocin and NADPH-diaphorase in magnocellular neurons of the paraventricular and the supraoptic nuclei of the hypothalamus. Neurosci. Lett. 171: 13-16 (1994).

Mizukawa, K., S. R. Vincent, P. L. McGeer and E. G. MCGEER: Distribution of reduced-nicotinamide-adeninedinucleotide-phosphate diaphorase-positive cells and fibers in the cat central nervous system. J. Comp. Neurol. 279: 281-311 (1989).

Monda, M., S. Amaro, A. Sullo and B. De Luca: Nitric oxide reduces the thermogenic changes induced by lateral hypothalamic lesion. J. Physiol. 88: 347-352 (1994).

Morley, J. E., V. B. Kumar, M. B. Mattammal, S. FARR, P. M. Morley and J. F. Flood: Inhibition of feeding by a nitric oxide synthase inhibitor: effects of aging. Eur. J. Pharmacol. 311: 15-19 (1996).

Murakami, T.: Expression of nitric oxide synthase in enkephalin and dynorphin systems of the rat hypothalamus. Fol. Endocrinol. 70: 967-978 (1994).

NaKamuRA, H.: NADPH-diaphorase and cytosolic urea cycle enzymes in the rat spinal cord. J. Comp. Neurol. 385: 616-626 (1997).

Nakamura, H., T. SAheki, H. IChIKI, K. NaKata and S. NAKAGAWA: Immunocytochemical localization of argininosuccinate synthetase in the rat brain. J. Comp. Neurol. 312: 652-679 (1991a).

Nakamura, H., T. Yada, T. Saheki, T. Noda and S. 
NAKAGAWA: L-argininosuccinate modulates L-glutamate response in acutely isolated cerebellar neurons of immature rat. Brain Res. 539: 312-315 (1991b).

Nelson, R. J., G. E. Demas, P. L. Huang, M. C. Fishman, V. L. Dawson, T. M. Dawson and S. H. SNYDER: Behavioural abnormalities in male mice lacking neuronal nitric oxide synthase. Nature 378: 383-386 (1995).

Olazabal, D. E. and A. Ferreira: Maternel behavior in rats with kainic acid-induced lesions of the hypothalamic paraventricular nucleus. Physiol. Behav. 61: 779784 (1997).

Otake, K. and D. A. Ruggiero: Monoamines and nitric oxide are employed by afferents engaged in midline thalamic regulation. J. Neurosci. 15: 1891-1911 (1995).

Palmer, R. M. and S. Moncada: A novel citrullineforming enzyme implicated in the formation of nitric oxide by vascular endothelial cells. Biochem. Biophys. Res. Commun. 158: 348-352 (1989).

Pow, D. V.: Immunocytochemical evidence for a glial localisation of arginine, and a neuronal localisation of citrulline in the rat neurohypophysis: implications for nitrergic transmission. Neurosci. Lett. 181: 141-144 (1994).

RABER, J. and F. E. BLOom: IL-2 induces vasopressin release from the hypothalamus and the amygdala: role of nirtic oxide-mediated signaling. J. Neutosci. 14: 6187-6195 (1994).

Ratner, S., H. Morell and E. Carvalho: Enzymes of arginine metabolism in brain. Arch. Biochem. Biophys. 91: 280-289 (1960).

Rettori, V., N. Belova, W. L Dees, C. L. Nyberg, M. Gimeno and S. M. McCann: Role of nitric oxide in the control of luteinizing hormone-releasing hormone release in vivo and in vitro. Proc. Acad. Sci. USA 90: 10130-10134 (1993).

SaheKI, T., T. Kusumi, S. Takada and T. Katsunuma: Studies of rat liver argininosuccinate synthetase. I. Physicochemical, catalytic, and immunochemical properties. J. Biochem. 81: 687-696 (1977).

Seilicovich, A., B. H. Duvilanski, D. Pisera, S. Theas, M. Gimeno, V. Rettori and S. M. McCanN: Nitric oxide onhibits hypothalamic luteinizing hormone-releasing hormone release by releasing gammma-aminobutyric acid. Proc. Nat. Acad. Sci. USA 92: 3421-3424 (1995a).

Seilicovich, A., M. Lasaga, M. Befumo, B. $\mathrm{H}$. Duvilanski, M. Del Carmen Diaz, V. Rettori and S. M. McCann: Nitric oxide inhibits the release of norepinephrine and dopamine from the medial basal hypothalamus of the rat. Proc. Nat. Acad. Sci. USA 92: 11299-11302 (1995b).

Siaud, P., M. Mekaouche, G. Ixart, M. Balmefrezol, L. Givalois, G. Barbanel and I. Assenmacher: A subpopulation of corticotropin-releasing hormone neurosecretory cells in the paraventricular nucleus of the hypothalamus also contain NADPH-diaphorase. Neurosci. Lett. 170: 51-54 (1994).
Siegel, A. and M. B. Shaikh : The neural bases of aggression and rage in the cat. Aggression Violent Behav. 2: 241-271 (1997).

Surh, L. C., S. M. Morris, W. E. O'Brien and A. L. BEAUDET: Nucleotide sequence of the cDNA encoding the rat argininosuccinate synthetase. Nucl. Acids Res. 16: 9352 (1988).

Surh, L. C., A. L. Beaudet and W. E. O'Brien: Molecular characterization of the murine argininosuccinate synthetase locus. Gene 99: 181-189 (1991).

Tashiro, N., T. Tanaka, T. Fukumoto, K. Hirata and H. NAKA0: Emotional behavior and arrhythmias induced in cats by hypothalamic stimulation. Life Sci. 36: 1087-1094 (1985).

Torres, G., S. LeE and C. Rivier: Ontogeny of the rat hypothalamic nitric oxide synthase and colocalization with neuropeptides. Mol. Cell Neurosci. 4: 155-163 (1993).

VAN DEN Pol, A. N.: The magnocellular and parvocellular paraventricular nucleus of rat: intrinsic organization. J. Comp. Neurol. 206: 317-345 (1982).

Van Den Pol, A. N., J. P. Wuarin and F. E. Dudek: Glutamate, the dominant excitatory transmitter in neuroendocrine regulation. Science 250: 1276-1278 (1990).

Villar, M. J., S. Ceccatelli, M. Ronnqvist and T. HöKFELT: Nitric oxide synthase increases in hypothalamic magnocellular neurons after salt loading in the rat. An immunohistochemical and in situ hybridization study. Brain. Res. 644: 273-281 (1994).

VinCENT, S. R. and H. KimURA: Histochemical mapping of nitric oxide synthase in the rat brain. Neuroscience 46: 755-784 (1992).

YAmAda, K., P. Emson and T. HöKfElT: Immunohistochemical mapping of nitric oxide synthase in the rat hypothalamus and colocalization with neuropeptides. J. Chem. Neuroanat. 10: 295-316 (1996).

\author{
Dr. Hiroyuki IsAyama \\ Department of Anatomy \\ Kyushu University School of Medicine \\ Maidashi, Higashi-ku, Fukuoka \\ 812 Japan \\ 諌 山 博之 \\ 812 福岡市東区馬出 3-1-1 \\ 九州大学医学部 \\ 解剖学第一講座
}

